\title{
Urgent endoscopy: What is the rush?
}

\author{
Alan Barkun MD ${ }^{1}$, Paul C Adams MD² Editor-in-Chief
}

A lan Barkun is Professor of Medicine and Chairholder of the DG Kinnear Chair in Gastroenterology at McGill University (Montreal, Quebec), where he headed the division between 1987 and 1997. He has a special interest in the assessment of emerging and existing technologies in digestive endoscopy, and most recently has completed original research in nonvariceal upper gastrointestinal (GI) bleeding. He headed a national collaboration that has resulted in three large registries. The best known, the Registry on Upper Gastrointestinal Bleeding and Endoscopy (RUGBE) initiative, has led to nine peer-reviewed publications. Many of the data generated have informed a recent international consensus conference led by the Canadian Association of Gastroenterology and chaired by Dr Barkun. He is currently completing a national, 44-site, Canadian Institutes of Health Research-funded cluster randomized trial assessing interventions aimed at improving adherence to guidelines in the management of patients with nonvariceal upper GI bleeding.

PA: There is a wide variability across the country in the prevalence of after hours endoscopy. You studied some of these data in the RUGBE study.

AB: We did, and noted that overall, $75 \%$ of patients found to have a nonvariceal cause of upper GI bleeding were endoscoped within $24 \mathrm{~h}$ of the time of presentation with bleeding. Interestingly, almost one-half were scoped within the first $12 \mathrm{~h}$, but the range was wide, with up to $10 \%$ of patients being endoscoped only $48 \mathrm{~h}$ later.

PA: Often we hear that the patient is too unstable to have an urgent endoscopy. After some resuscitation, the patient is now too stable to need an urgent endoscopy.

$\mathrm{AB}$ : Indeed this is a common 'complaint' of primary caregivers levied toward endoscopists. However, we need to remember that patients must be as stable as possible from a cardiorespiratory point of view before considering the endoscopy, including, if appropriate, the need for intubation such as in cases of profuse active bleeding. Of course, in rare cases, an individual decision must be made as to whether the patients are as stable as they are going to be. In very rare cases, the endoscopy may need to be performed in the operating suite immediately before surgery if the situation is catastrophic (and usually if variceal bleeding is unlikely). With regard to a patient being too stable to endoscope, anytime within the first $24 \mathrm{~h}$ is appropriate and evidence-based, with the proviso that the endoscopy should be performed promptly if it is likely to immediately affect disposition of the patient (for example, in the case of a possible immediate discharge home from the emergency room). Rarely, patients with very active bleeding may need to be endoscoped quickly if surgery is being contemplated and the source of bleeding is undefined. Additionally, rare cases may also require earlier intervention such as for Jehovah's witnesses because one may not be able to 'waitand-see' in the face of possible ongoing bleeding and an already low hemoglobin level that cannot be corrected with transfusional support.

PA: Can you comment on the evidence that endoscopic intervention applied early after presentation effects survival, blood transfusions or any other outcome measure?

AB: Randomized controlled trial evidence has shown that early endoscopy, as defined by within $24 \mathrm{~h}$ of presentation, leads to a decrease in length of hospital stay and blood transfusion requirements. No improvements in rebleeding or surgery have been documented with early endoscopy, although a recent observational study (1) has suggested indirect evidence for a decreased mortality, possibly attributable to its performance. Guidelines suggest endoscoping patients within $24 \mathrm{~h}$ of presentation, if local resources allow it. Earlier intervention is not warranted except for the rare scenarios discussed above.

PA: There is a significant cost to providing an after hours endoscopy team. Do you think this should be standard practice at most urban hospitals?

AB: Recent data from the United Kingdom suggest that the availability of such timely expertise may result in improved patient outcomes, and guidelines clearly endorse this approach.

PA: What are the most compelling indications for immediate endoscopy?

AB: If I understand your question correctly, you are asking about endoscopy in general. Indications would include suspected variceal bleeding, an impacted bolus or foreign body in the esophagus, especially if cephalad, with possible airway compromise, and as discussed above, in selected cases of upper GI bleeding. As for lower GI bleeding, the recommended timing of a colonic preparation in the acute setting (for which there are weak supportive data) is an emergent, and not immediate one. Colonoscopy can be performed thereafter, usually within $12 \mathrm{~h}$ to $24 \mathrm{~h}$ following the initial presentation.

\footnotetext{
${ }^{1}$ Division of Gastroenterology, McGill University, Montreal, Quebec; ${ }^{2}$ University Hospital, London, Ontario

Correspondence: Dr Alan Barkun, Division of Gastroenterology, McGill University, Montreal, Quebec

Telephone 514-934-8309, fax 514-934-8531, e-mail alan.barkun@muhc.mcgill.ca

Received and accepted for publication June 4, 2009
} 
PA: Can you predict the future in this area?

AB: With the availability of existing data, the development of radiological hemostatic techniques more effectively adapted to acute lower GI bleeding and the impetus toward an improved medical doctor lifestyle, it is likely that less-urgent endoscopy will be performed at night. I will, however, leave you with a sobering recent finding from two observational studies $(1,2)$ : as in many other conditions, the mortality of patients with upper GI bleeding is greater in individuals presenting after hours and on the weekend. What is unclear is whether this observation is attributable to a self-selected group of patients presenting earlier because they are sicker or an inequity in resource availability in these off-hours, or a mix of both.

\section{REFERENCES}

1. Ananthakrishnan AN, McGinley EL, Saeian K. Outcomes of weekend admissions for upper gastrointestinal hemorrhage: a nationwide analysis. Clin Gastroenterol Hepatol 2009;7:296-302e1.

2. Shaheen AA, Kaplan GG, Myers RP. Weekend versus weekday admission and mortality from gastrointestinal hemorrhage caused by peptic ulcer disease. Clin Gastroenterol Hepatol 2009;7:303-10. 


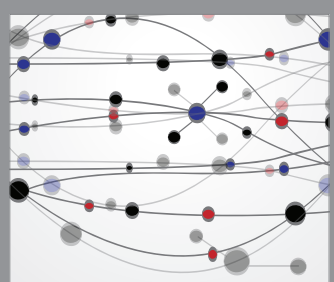

The Scientific World Journal
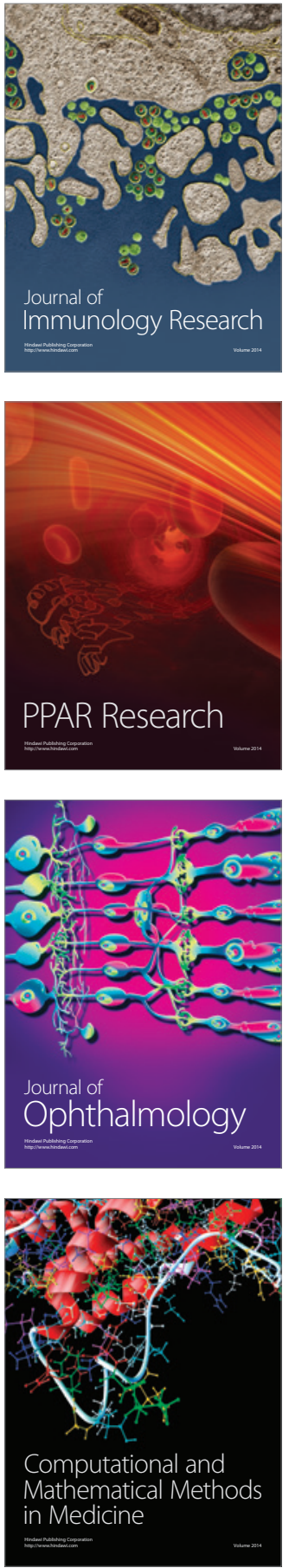

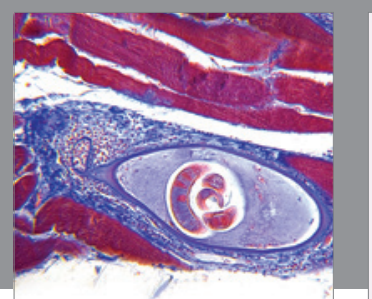

Gastroenterology Research and Practice

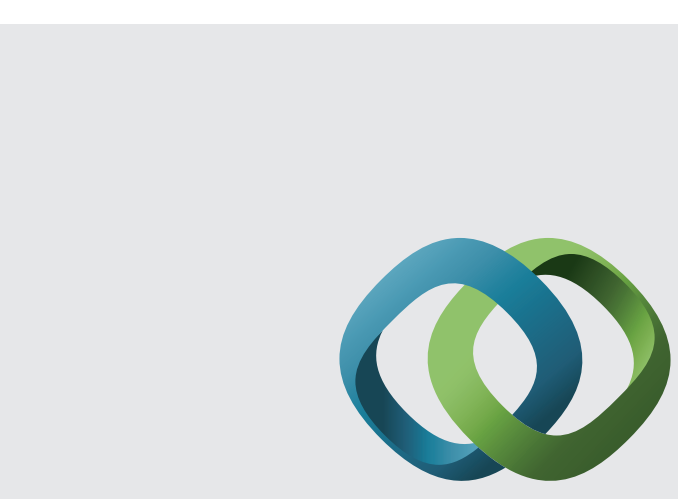

\section{Hindawi}

Submit your manuscripts at

http://www.hindawi.com
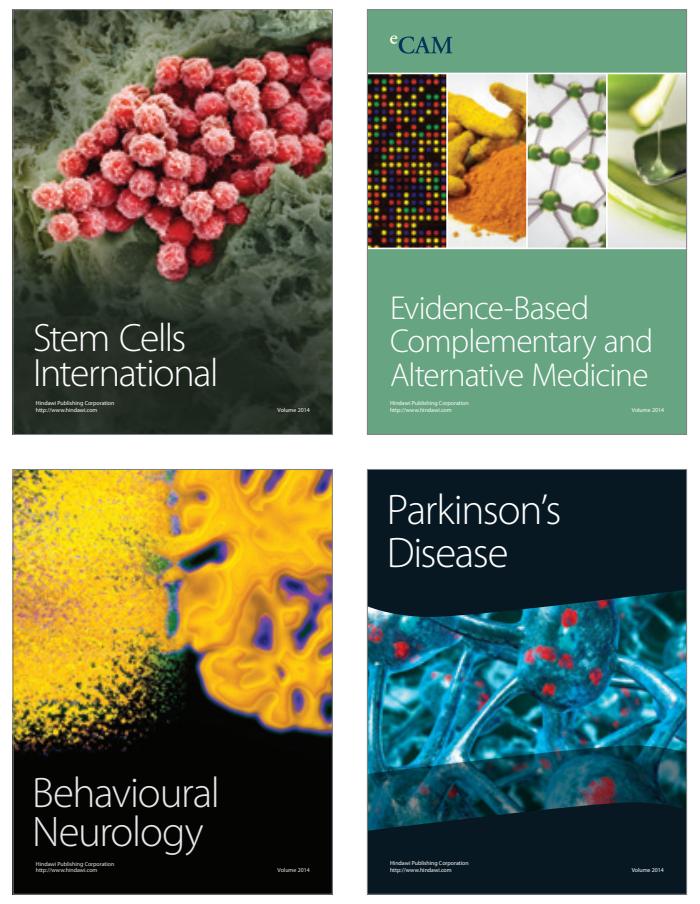
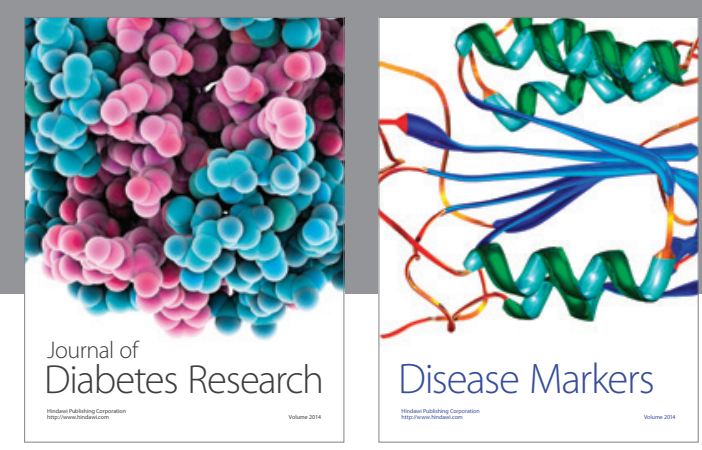

Disease Markers
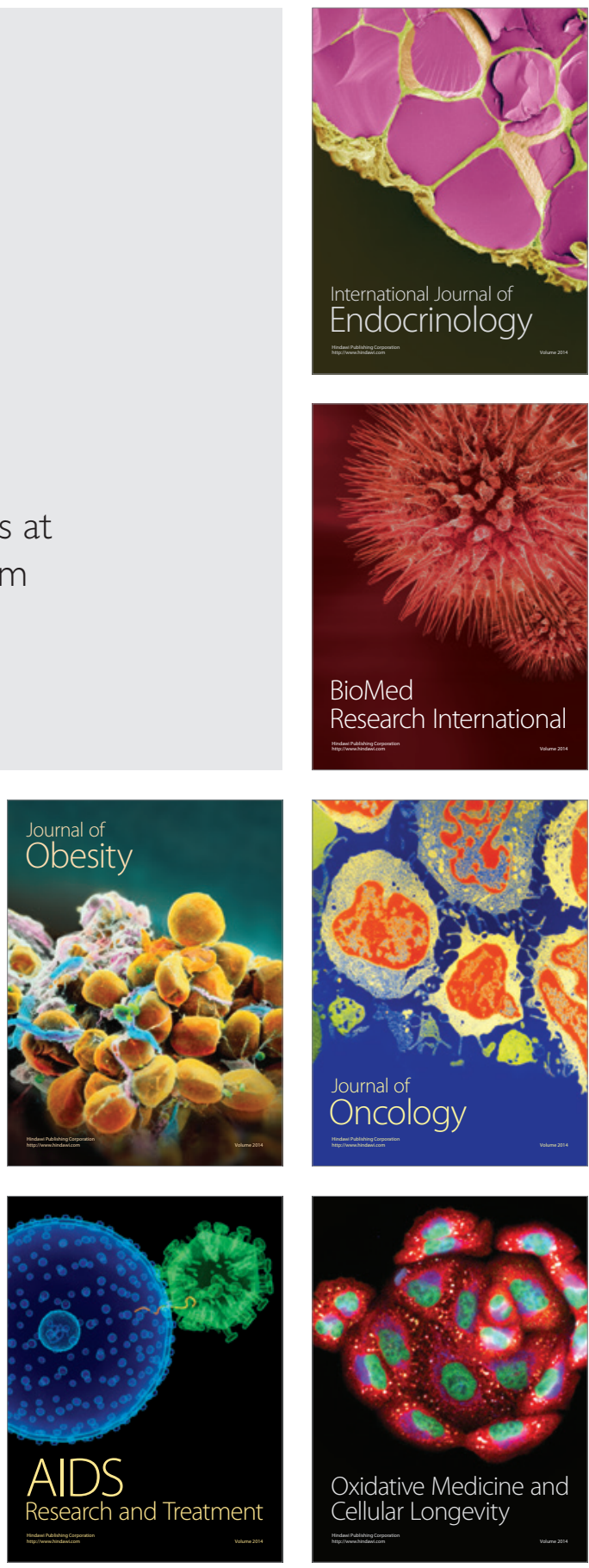